\title{
The Rise of an Athlete Brand: Factors Influencing the Social Media Following of Athletes
}

\author{
Yiran Su, Bradley J. Baker, Jason P. Doyle, and Thilo Kunkel
}

Yiran Su, PhD, is an assistant professor of sport management in the Department of Kinesiology at the University of Georgia. Her research interests include consumer identity and behavior, branding in sport business, global marketing strategy, and data science. Bradley J. Baker, $\mathrm{PhD}$, is an assistant professor of sport management in the Isenberg School of Management at the University of Massachusetts Amherst. His research interests include research methods, brand building via social media, sport consumer behavior and loyalty, and machine learning and artificial intelligence.

Jason P. Doyle, PhD, is a lecturer in the Department of Tourism, Sport, and Hotel Management at Griffith University. His research interests include consumer behavior within sport and event settings, fan development, strategic branding, examining the links between sport and event involvement and positive social-psychological well-being.

Thilo Kunkel, PhD, is an associate professor in the Sport and Recreation Management Department at the School of Sport, Tourism, and Hospitality Management at Temple University. His research interests include strategic management and marketing, consumer engagement in a digital environment, and brand relationships.

\begin{abstract}
Athlete brands exist within a network of brand relationships. Thus, considering the joint influences of related brands at different levels (league, team, and athlete) is essential for understanding how athlete brands are built. We focus on growth factors impacting athletes' social media followings (Twitter and Instagram) around the critical juncture of team transfer periods. We use data from the NFL Draft, because this moment in time provides a key opportunity to capture combined influences from league-, team-, athlete-, and platform-related factors on athlete brand development. Through comparing a large sample of athlete social media followings before and after the draft, we identify immediate changes as athletes start their professional careers. Results indicate examining multiple factors in the same model is essential for understanding the role each plays in building athlete brands. The league and team represent master brands into which an athlete brand is integrated, and consequently athlete brands are provided with benefits from these new brand relationships. Results further demonstrate network effects, highlighting the importance of possessing a strong brand before a high-profile event.
\end{abstract}

Keywords: athlete branding, social media, network effect, brand relationship, nonparametric regression http://doi.org/10.32731/SMQ.291.302020.03

\section{Introduction}

An athlete's personal brand is one of their most valuable assets. A strong athlete brand is associated with greater earnings from salary, transfer fees, and endorsement deals (Parmentier \& Fischer, 2012) and can help maintain a positive image even when on-field performance declines (Pegoraro \& Jinnah, 2012). Social media platforms allow athletes to construct their personal brand without much financial investment, as they are easy to use and have other benefits related to reach and accessi- bility (cf., Eagleman, 2013; Geurin-Eagleman \& Burch, 2016). Consequently, an athlete's social media profiles are now an inseparable part of their brand and a key mechanism for athletes to pursue branding initiatives (Geurin, 2017). For example, soccer player Michael Lahoud leveraged his community efforts and social media following to negotiate a contract with a new team and to develop a unique and distinct athlete brand (Kunkel, Scott, \& Beaton, 2016).

As the value of athlete brands is increasingly recognized in the industry, athletes' social media perfor- 
mance has garnered particular interest among academics and practitioners. Building on research establishing the factors that contribute to growth and success of athlete brands (e.g., Arai, Ko, \& Kaplanidou, 2013; Arai, Ko, \& Ross, 2014), researchers have explored how athletes manage their self-presentations on social media (e.g., Geurin-Eagleman \& Burch, 2016). However, one area that is not well understood is the combined effects that brands at different levels (e.g., league, team, and athlete) have on one another. Athlete brands are inherently influenced by their affiliations with particular leagues and teams (Kunkel, Funk, \& Hill, 2013; Kunkel, Funk, \& Lock, 2017). This manifests in the proliferation of interactions between sport entities, athletes, and fans across social media (Gibbs, O'Reilly \& Brunette, 2014; Filo, Lock, \& Karg, 2015). For example, researchers have demonstrated that star player posts account for close to $40 \%$ of the content posted by the Liverpool Football Club on Twitter (Parganas, Anagnostopoulos, \& Chadwick, 2015) and approximately $35 \%$ of posts by the team on Instagram (Anagnostopoulos, Parganas, Chadwick, \& Fenton, 2018). While such insights establish that sport brands are inherently linked, opportunities remain to advance empirical evidence demonstrating how related sport brands impact consumer behavior directed toward athlete brands.

In this article, we investigate factors associated with the growth of athlete brands on social media. We specifically focus on how an athlete joining a new team or league influenced their online following. For example, 16,533 male and 696 female professional soccer players transferred to new teams in 2018 (FIFA, 2019a; 2019b). Events related to player movement (e.g., trade deadlines and the start of free agency period) are associated with increased social media following (Watanabe, Yan, \& Soebbing, 2015). Meanwhile, the start of every professional career inherently requires forging new brand relationships between the athlete, their league, and their team.

The current research contributes to better understanding sport brand architecture, athlete branding, and the jointly differential effects of league-, team-, athlete-, and platform-related factors on the growth of athletes' social media follower numbers. Strengths of our approach include use of actual behavioral data (social media following behavior), use of quantitative methods that complement prior social media research dominated by content analyses, and replication of results across Twitter and Instagram, demonstrating that our findings are robust to choice of social media platform. Our results move beyond looking at sport brands in isolation and show examined factors work in concert, and thus the findings provide guidance to practitioners on how to manage their branding efforts within dynamic brand architecture portfolios.

\section{Literature Review}

\section{Schema Theory and Brand Architecture}

To frame this investigation and better understand how perceptions toward athlete brands may be influenced by other brands, we utilize schema theory and the concept of brand architecture. Schema theory outlines that the associations consumers link to a brand are influenced by both direct experience and knowledge about the general environment surrounding that brand (Gwinner \& Eaton, 1999; Lynch \& Schuler, 1994). According to schema theory, when an individual encounters new information about a brand, the information is evaluated within the existing schema that is attached to the brand and is subsequently integrated into the existing schema (Davvetas \& Diamantopoulos, 2016). Consequently, these new relationships can influence how consumers evaluate the respective brands involved in the portfolio. Thus, consumer perceptions of athletes are influenced by other brands that are related to the athlete.

In line with schema theory, brand architecture research provides a framework to understand the influence of related brands on athlete brands and has been used to explain the impact of league brands on team brands and vice versa (Kunkel et al., 2013; Kunkel et al., 2017; Kunkel, Funk, \& King, 2014). Sport brands are dynamic and operate within a hierarchy consisting of master brands and sub-brands (Kunkel et al., 2013), and changes within the hierarchy impact brands within the portfolio. From a conceptual perspective, individual athletes operate as sub-brands that are visibly connected with their respective teams and representative leagues (e.g., Williams, Kim, Agyemang, \& Martin, 2015). For example, research has demonstrated the influence athletes have on increasing consumer demand for specific leagues and events (Shapiro, DeSchriver, \& Rascher, 2017) and has shown that athlete brands impact perceptions of team brands, particularly when athletes transfer to a new team (Daniels, Kunkel, \& Karg, 2019; Kunkel et al., 2013; Kunkel at al., 2014). Similarly, research focused on the development of athlete brands indicates that league and team brands act as antecedents into how consumers perceive athlete brands (e.g., Hasaan, Kerem, Biscaia, \& Agyemang, 2018), yet this work remains conceptual. Therefore, opportunities exist to build on the above knowledge to empirically determine how related brands may impact consumer behavior toward athlete brands. Within the present research, we examine how athlete brands are impacted when an athlete transfers teams and thus simultaneously modifies the related master brands within their brand architecture portfolio. 
In doing so, we specifically focus on the impacts that occur on social media.

\section{Athlete Branding on Social Media}

Social media platforms represent a powerful means for athletes to brand themselves and develop relationships with fans (Kunkel et al., 2016). To date, research has explored social media branding practices from two main perspectives: the experiences of athletes and patterns of fan engagement. Researchers have identified motives for athletes' branding behavior on social media and revealed what athletes post and how fans respond to those posts on both Twitter and Instagram platforms by using in-depth interviews and conducting content analysis (e.g., Geurin, 2017; Geurin-Eagleman \& Burch, 2016; Hambrick, Frederick, \& Sanderson, 2015; Pegoraro, 2010). These studies indicate that the engagement of an athlete's social media profile is contingent on how athletes operate their digital self-presentations.

While the existing approaches highlight the important role of social media in promoting an athlete brand, they do not fully reflect the unique characteristics of athlete branding and social media. First, the personal brand of an athlete, who competes within the structure of a professional sport league, is not constructed in isolation but under the impact of both team and league brands (cf., Daniels et al., 2019; Kunkel et al., 2014; Kunkel et al., 2017). Notably, previous work on social media has assessed the brand building opportunities available to athletes who compete in Olympic sports and, thus, develop their brands largely on their own (e.g., Geurin, 2017). However, little is known about the combined effects of league- and team-level factors on an athlete's brand.

Second, studies on digital athlete branding have not considered the impact of network effects on building or maintaining the athlete brand. That is, the influence of the size of an existing fan base on generating new interest from other consumers (cf., Katona, Zubscek \& Sarvary, 2011). Research in the general marketing literature has found that individuals who are related to already engaged consumers on social network sites tend to adopt a new product earlier than those with fewer connections (e.g., Nejad, Sherrell, \& Babakus, 2014). The reason is that brands that have a greater number of followers are connected to more sales leads as opposed to the less popular brands (Katona et al., 2011).

Many social media platforms, including Twitter and Instagram, rely on machine learning-driven algorithms that consider variables including a user's number of followers and past engagement (among other factors) when determining which posts to present to other users (Constine, 2018; Koumchatzky \& Andreyeyev, 2017). Posts from accounts with more followers and that have generated greater past engagement are prioritized and, thus, seen by more people. Research on the following behavior of teams' Twitter accounts revealed a positive relationship between the sum of players' followers and the increase of teams' network size (Watanabe, Yan, \& Soebbing, 2016). This effect is also related to the double jeopardy effect than competitors with smaller brands (e.g., Baker, McDonald, \& Funk, 2016; Doyle, Filo, McDonald, \& Funk, 2013; Fujak, Frawley, McDonald, \& Bush, 2018). In the current study, we focus on the initial interest of consumers in athlete brands, considering network effects both of the athlete's extant network size as well as the affiliated team's network size.

\section{Hypothesis Development}

\section{League-Related Influence}

From a brand building perspective, the external environment surrounding a brand has a significant influence on the brand's positioning (Vallaster \& de Chernatony, 2005). Within the sport context, high-profile events can be important triggers for the celebrification of an athlete, resulting in a significant boost to their social media engagement (Marwick, 2015). The league provides a platform for athletes to gain brand awareness. For example, the National Football League (NFL) Draft is a highly promoted league event at which teams take turns selecting athletes for whom they receive exclusive negotiating rights. Earlier round picks represent a quality signal, as the athlete is integrated in the brand architecture of the league as a sub-brand (Kunkel et al., 2017; Rubin, 1978). Generally, the first round attracts the most media coverage, and the audience declines for subsequent rounds (Pucci, 2017) as the strength of the quality signal decreases (i.e., teams are more involved in more strategic planning and compete to select the best athletes in earlier rounds compared to later rounds). Therefore, we hypothesize the round in which athletes are selected impacts their increase of followers.

Hypothesis 1: Selection in early rounds of the draft is associated with a greater increase in followers than is selection in later rounds of the draft.

\section{Team-Related Influence}

Based on schema theory and brand architecture, once athletes are selected by a team, their personal brand image and the meaning of their brand in consumers' minds is connected to the team's brand (Yang, Shi, \& Goldfarb, 2009). Similar to the league-team brand relationship (Kunkel et al., 2013), the team-athlete brand relationship should induce image transfer once an athlete joins a new team. Individuals who identify as team fans will develop an increased liking for athletes who are drafted to their team based on the tenets of 
social identity theory (c.f., Tajfel \& Turner, 1979). In this case, the athlete will become a member of the ingroup upon joining the team, reducing the psychological distance between the athlete and the fan as well as eliciting positive attitudinal and behavioral responses from the fan community (Doyle, Filo, Lock, Funk, \& McDonald, 2017; Lock \& Funk, 2016; Lock \& Heere, 2017). Therefore, the market share of the athletes' new team reflected on social media should impact their increase in followers, and we hypothesize a positive effect from the team brand to the athlete brand with respect to social media followers.

Hypothesis 2: The number of social media followers of the new team is positively associated with the increase in athletes' social media following.

\section{Athlete-Related Influence}

The existing number of followers a social media user possesses has been widely used as an indicator of information amplification potential, as athletes with a larger number of followers get more exposure based on the algorithms used by social media platforms (Constine, 2018; Cappelletti \& Sastry, 2012). This cumulative advantage is coined the Matthew effect in the literature (i.e., "the rich get richer at a rate that makes the poor become relatively poorer," Merton, 1968, p. 62), which suggests the size of athletes' pre-draft social media presence influences the additional followers they gain after the draft. That is, the number of pre-existing followers that an athlete possesses is likely to have an influence on the athlete's brand (e.g., Baker et al., 2016; Doyle et al., 2013; Fujak et al., 2018), which, in line with the network effect, indicates brands with larger consumer bases have a higher capacity to attract new consumers (Katona et al., 2011). Thus, such ripple effects of popularity imply a player who has more followers than others before the draft will attract more new followers after the draft (Dennett, Nepal, Paris, \& Robinson, 2016). Therefore, we hypothesize that an athlete's number of followers before the draft is positively associated with the increase in followers after the draft.

Hypothesis 3: The number of social media followers of an athlete prior to the league event is positively associated with the increase in athlete's social media following.

\section{Platform-Related Influence}

Certain social media platforms enable certifiable user accounts with verification to establish their authenticity. Unlike traditional media, social media can lack conventional, reliable indicators of authorship, which represents a key component of source credibility (Sundar, 2007). To aid in resolving this dilemma, some social media platforms mark accounts that have been authenticated as belonging to particular high-pro- file individuals or brands. A verified badge provides evidence of legitimacy to a social media account (Ottovordemgentschenfelde, 2017). Social media users view verified accounts as more credible (Zhang, Peng, Zhang, Wang, \& Zhu, 2014), and a verification badge can be viewed as a status symbol (Grabowicz, Babaei, Kulshrestha, \& Weber, 2016). Account verification is therefore expected to enhance positive network effects that allow athletes to grow their follower counts. We hypothesize that verified athlete accounts will benefit from a greater increase in followers than non-verified accounts upon being drafted.

Hypothesis 4: The increase in social media followers following the league event is greater for verified accounts than for non-verified accounts.

\section{Method}

\section{Research Context}

Within this study, we examine the NFL Draft as an event that facilitates athletes to establish new relationships within their respective brand architecture structures. Each April, the NFL conducts a highly-publicized league entry draft, where all teams take turns selecting athletes for whom they receive exclusive negotiating rights. The NFL Draft spans seven rounds held over three days (round one on Thursday evening, rounds two and three on Friday evening, and rounds four through seven on Saturday afternoon) and is extensively covered by online, television, and print media. Each year, every team is granted the right to select one athlete in each round, based on reverse order of standing in the previous season. Selection rights can be, and often are, traded, so it's possible for a given team to gain additional selections in any given round. The league can additionally assign up to 32 compensatory picks to teams that have incurred a net loss of players to free agency (player transfers to other teams after contract expiration) in the previous year. In total, approximately 250 athletes are drafted and subsequently join the league and their new teams each year. Thus, the NFL Draft provided an opportune scenario to examine the immediate effects experienced by athlete brands as they suddenly became affiliated with more established brands (e.g., at the team level), allowing us to examine these effects as multiple athletes simultaneously joined new teams and a new league rather than collecting this information on an individual transfer basis.

\section{Participants and Data}

Data for the current study were generated by collecting profile information from public social media accounts maintained by prospective NFL draftees immediately preceding and following the 2017 NFL Draft. We 
manually searched for and recorded handles (account names) associated with accounts of athletes who declared for the NFL Draft on two social media platforms that are widely used as branding tools: Instagram and Twitter (Statista, 2018). In total, public profiles of 162 athletes were assessed, of which 151 had Twitter profiles and 121 had Instagram profiles. Of the scraped athletes, $67.5 \%$ of Twitter accounts were verified and $76.9 \%$ of Instagram accounts were verified.

\section{Data Collection}

We developed a custom web scraper to identify and gather the required information from athletes' Twitter and Instagram profiles. Data were collected at two points: two days before (April 25, 2017) and two days after (May 1, 2017) the 2017 NFL Draft. For each data collection period, the web scraper extracted key data (followers, biography, and a dummy variable indicating whether or not the account was verified). The final dataset for analysis comprised, for each athlete, the round in which the athlete was selected in the draft, social media followers of the drafting team, initial number of social media followers, the increase in social media followers, and account verification status. The increase in social media followers, athletes' followers before the draft, and teams' followers were all right-skewed; therefore, each variable was log-transformed prior to analysis. The selection round for each athlete was dummy coded and six variables, representing rounds one through six, were included in the model. Account verification status was also dummy coded $(1=$ verified; $0=$ not verified $)$.

\section{Analysis}

We used R 3.4.4 software to analyze the data. We ran multiple linear regression analyses to test the hypotheses. The dependent variable was the increase in social media followers (log-transformed). The independent variables included two log-transformed variables (initial number of social media followers and social media followers of the drafting team) and two dummy coded variables (round and verification). Round 7 was selected as the baseline in the regression. We tested for heteroscedasticity because of the assumptions for Ordinary Least Squares (OLS) regression by using the White Test (Hill, Griffiths \& Lim, 2011). To adjust for heteroscedasticity, which violated the assumption in OLS regression that the error term had constant variance across all values of the independent variables (Hayes \& Cai, 2007), we calculated heteroscedasticity-consistent standard errors before we performed the regression analyses (Hill et al., 2011).

After testing the linear model, we adopted a nonparametric approach to describe the impact path of each independent variable individually and provide insight into further parametric analyses (Rust, 1998). Log transforming parametric models results in lack of contextual understanding at the granular level because of the normalization process (McCall, 2018). For example, the linear model was unable to detect instances where teams with an above-average number of followers (e.g., Dallas Cowboys, New England Patriots) had several late-round picks, yet the nonparametric approach can graphically depict these situational relationships between the independent variables and the dependent variable in a straight-forward manner. Consequently, we performed nonparametric kernel regression with the original dataset to reveal relational patterns between variables, which adjusts for errors caused by heteroscedasticity (Lee 1996; Steiner, Brezger, \& Belitz, 2007). Therefore, each of our hypotheses were subsequently tested.

\section{Results}

Results suggest that athletes drafted in earlier rounds benefitted more from increased social media followers than those selected in later rounds. Figure 1 presents an overview of the increased followers across platforms, as impacted by the selection round. Results demonstrate that the drafting teams had high variances in terms of their follower numbers, with a standard deviation of $720,221(M=1,303,372)$ on Twitter and a standard deviation of $594,580(M=872,060)$ on Instagram. Similarly, analyses indicated substantial heterogeneity was present among the initial followers of the athletes on both platforms. The athletes' initial Twitter followers had a mean of 19,596 and a standard deviation of 54,028, and the initial Instagram followers had a mean of 21,929 and a standard deviation of 40,682 . Furthermore, the correlation between two continuous variables (followers of drafting teams and initial followers of the players) was .061 in the context of Twitter and .060 in the context of Instagram. Figure 2 depicts the increased followers across platforms impacted by account verification. Descriptive statistics of the variables are presented in Table 1.

The results of the multiple linear regression analyses are presented in Table 2. The model explains $76.9 \%$ of the increase of Twitter followers and $83.6 \%$ of Instagram followers for the examined time period. As we hypothesized, being selected at the early rounds of the draft was associated with a greater increase in followers across both platforms. Therefore, Hypothesis 1 was supported. As illustrated in the regression results, the effect of round diminished as the draft progressed. It is noteworthy that some selection rounds did not entail significantly higher number of new followers compared to the baseline round (Round 7). These results suggest a need 


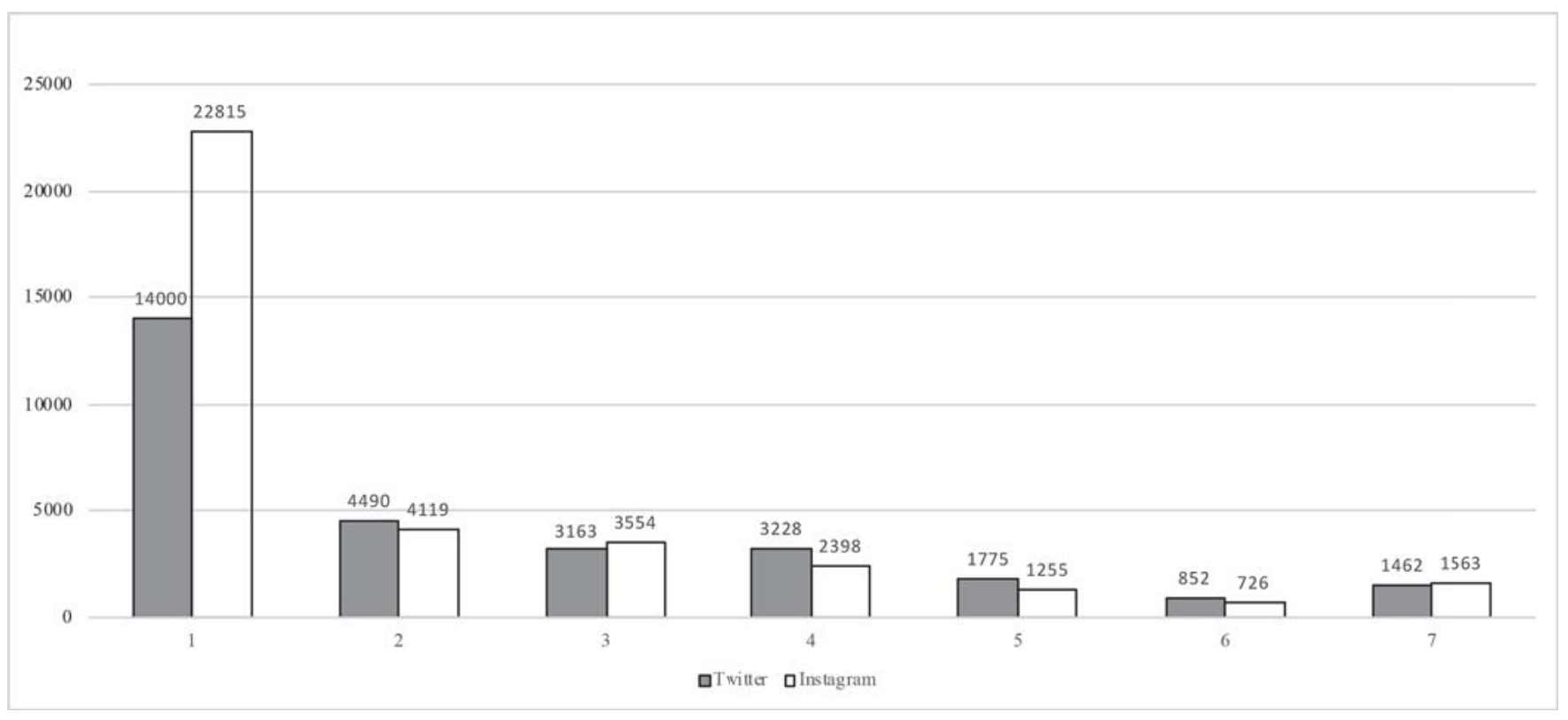

Figure 1. Athletes' increase in followers by rounds

to assess how factors impacted the dependent variable contextually by using a nonparametric model design that can capture the essential shape of the data beyond the statistical significance level (Van Heerde, 2017). As we also hypothesized, social media followers of the drafting team $(\mathrm{H} 2)$ and the initial number of social media followers (H3) were significantly related to the increase in social media followers in both Instagram and
Twitter contexts. Therefore, Hypothesis 2 and Hypothesis 3 were supported. Regarding the status of verification, verified Instagram profiles had a significantly higher likelihood to yield more followers after the draft. However, there was no significant difference between the verified athlete profiles and non-verified athlete profiles on Twitter. Hence, Hypothesis 4 was only supported in the context of Instagram. Overall, the results of the linear

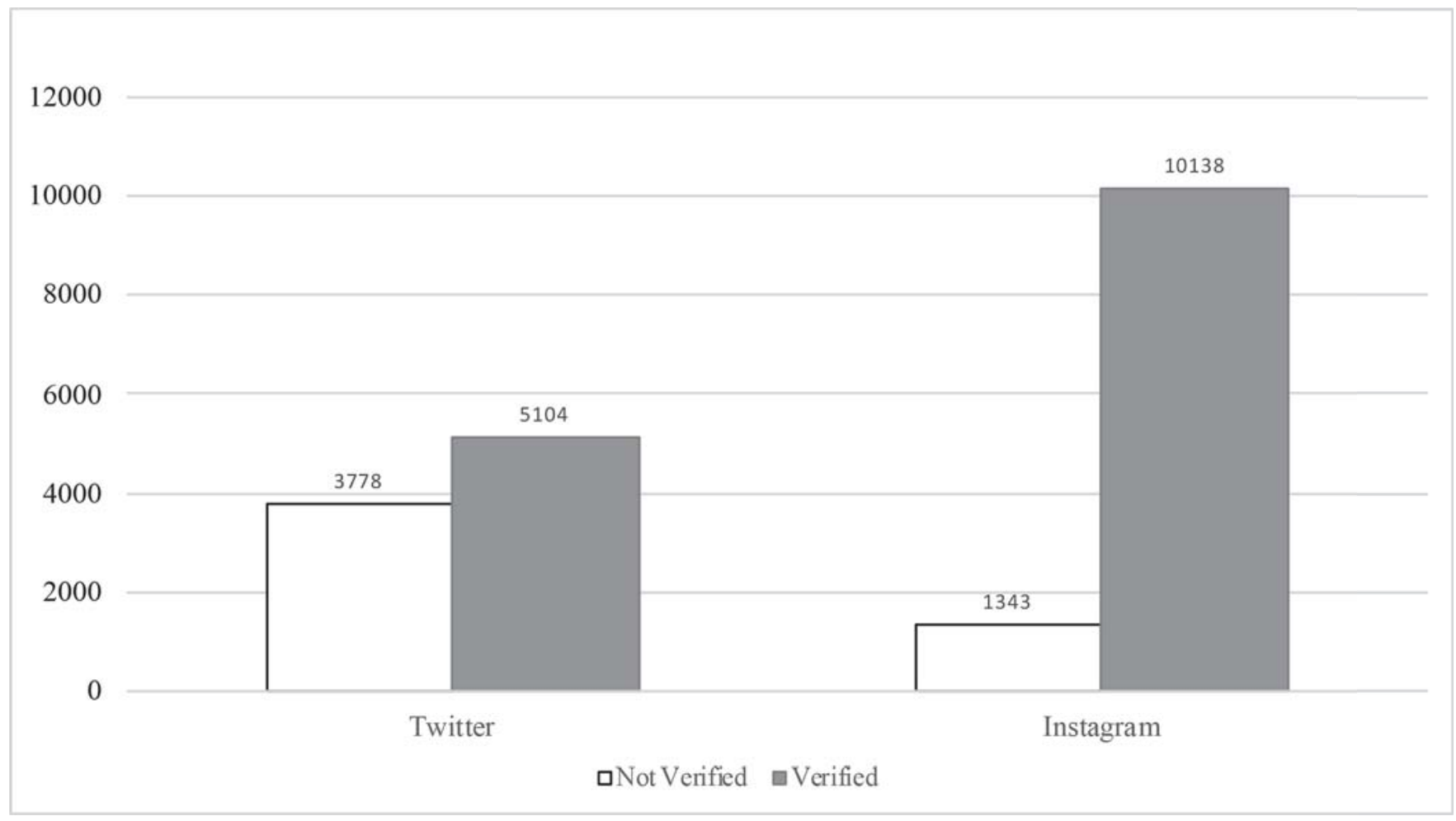

Figure 2. Athletes' increase in followers by verified status 
Table 1. Descriptive Statistics of Variables by Platform

\begin{tabular}{lllllll}
\hline & \multicolumn{2}{c}{ Twitter } & & \multicolumn{2}{c}{ Instagram } \\
\cline { 2 - 3 } \cline { 5 - 6 } & \multicolumn{1}{c}{$\boldsymbol{M}$} & \multicolumn{2}{c}{$S \boldsymbol{S D}$} & & $\boldsymbol{M}$ & \multicolumn{1}{c}{$\boldsymbol{S D}$} \\
\hline Initial number of social media followers & 19596 & 54028 & & 21929 & 40682 \\
Social media followers of the drafting team & 1303372 & 720221 & & 872060 & 594580 \\
Increase in followers & 4705 & 7480 & & 6077 & 14495 \\
& Frequency & $\%$ & & Frequency & $\%$ \\
Verified & 102 & 67.5 & & 93 & 76.9 \\
\hline
\end{tabular}

regression analysis provided a generalizable preliminary understanding of how different factors impacted the extent to which athlete social media profiles benefited from an increase in followers post-draft.

Results of the nonparametric kernel regression analysis are presented in Figure 3. The first partial nonparametric regression model (Figure 3: Round Effect) illustrates a general trend of steady decrease in newly acquired followers based on the athlete's draft selection round. The small uptick present in Round 7 further supports the nonsignificant results of some other rounds in the linear regression model, because teams with large fanbases drafted more than one player in the final round (i.e., the Dallas Cowboys picked three players and the Seattle Seahawks picked two players). The second partial nonparametric regression analysis (Figure 3: Teams' Followers Effect) depicts the combined effect from the team- and athlete-level. While the regression results show that team following was a salient factor, it could not compensate for athletes who had not developed a social media presence before the draft. For example, the Seahawks (Instagram followers $=1.93$ million) selected athletes whose average number of followers before the draft was only one-third of the average followers of all athletes $(9,019$ vs. 28,006$)$. The third nonparametric model, in relation to athlete's predraft followers (Figure 3: Athlete's Followers Effect), demonstrates differences in athletes' network sizes across the platforms. As the athletes' initial followers on Twitter had a higher standard deviation than the ones on Instagram, we found outliers on the graphic, leading to an irregular pattern.

\section{Discussion}

Overall, our results contribute to knowledge surrounding how sport brand relationships impact consumer behavior in the social media context. These findings demonstrate athlete brands operate as sub-brands within brand architecture structures and that their associated master brands influence the extent to which the athlete brand may benefit when the athlete's brand portfolio changes. We analyzed data from two social networking sites to discover important factors that influence consumer interest in athlete brands. Our findings extend the athlete branding literature by demonstrating the jointly differential effects of league-, team-,

Table 2. Results of Multiple Linear Regressions

\begin{tabular}{|c|c|c|c|c|c|c|}
\hline \multirow[b]{2}{*}{ Variable } & \multicolumn{3}{|c|}{ Twitter } & \multicolumn{3}{|c|}{ Instagram } \\
\hline & $B$ & $S E$ & $t$ & B & $S E$ & $t$ \\
\hline Constant & -7.78 & 1.54 & $-5.10^{* * *}$ & -7.96 & 1.53 & $-5.20^{\star * *}$ \\
\hline Social media followers of the drafting team (In) & 0.88 & 0.10 & $8.43^{* * *}$ & 0.76 & 0.076 & $7.78^{\star * *}$ \\
\hline Initial number of social media followers (In) & 0.30 & 0.04 & $8.07^{\star * *}$ & 0.49 & 0.08 & $6.33^{\star * *}$ \\
\hline Round 1 & 1.93 & 0.20 & $9.73^{* * *}$ & 1.95 & 0.26 & $7.24^{\star * *}$ \\
\hline Round 2 & 0.51 & 0.11 & $4.67^{* * *}$ & 0.45 & 0.11 & $3.95^{\star * *}$ \\
\hline Round 3 & 0.204 & 0.075 & $2.71^{\star *}$ & 0.16 & 0.09 & 1.72 \\
\hline Round 4 & 0.15 & 0.05 & $2.76^{* *}$ & 0.02 & 0.06 & 0.26 \\
\hline Round 5 & 0.09 & 0.04 & $2.15^{\star}$ & 0.06 & 0.04 & 1.75 \\
\hline Round 6 & -0.026 & 0.04 & -0.66 & 0.02 & 0.04 & 0.56 \\
\hline Verification & -0.09 & 0.11 & -0.84 & 0.49 & 0.18 & $2.74^{\star \star}$ \\
\hline$R^{2}$ & 0.77 & & & 0.85 & & \\
\hline Adj. $R^{2}$ & 0.76 & & & 0.84 & & \\
\hline $\mathrm{F}$ & $49.61^{* *}$ & & & $68.35^{* *}$ & & \\
\hline
\end{tabular}

Note: ${ }^{\star} p<.05 ;{ }^{* *} p<.01 ;{ }^{* *} p<.001$; Round 7 is the baseline drafting round 

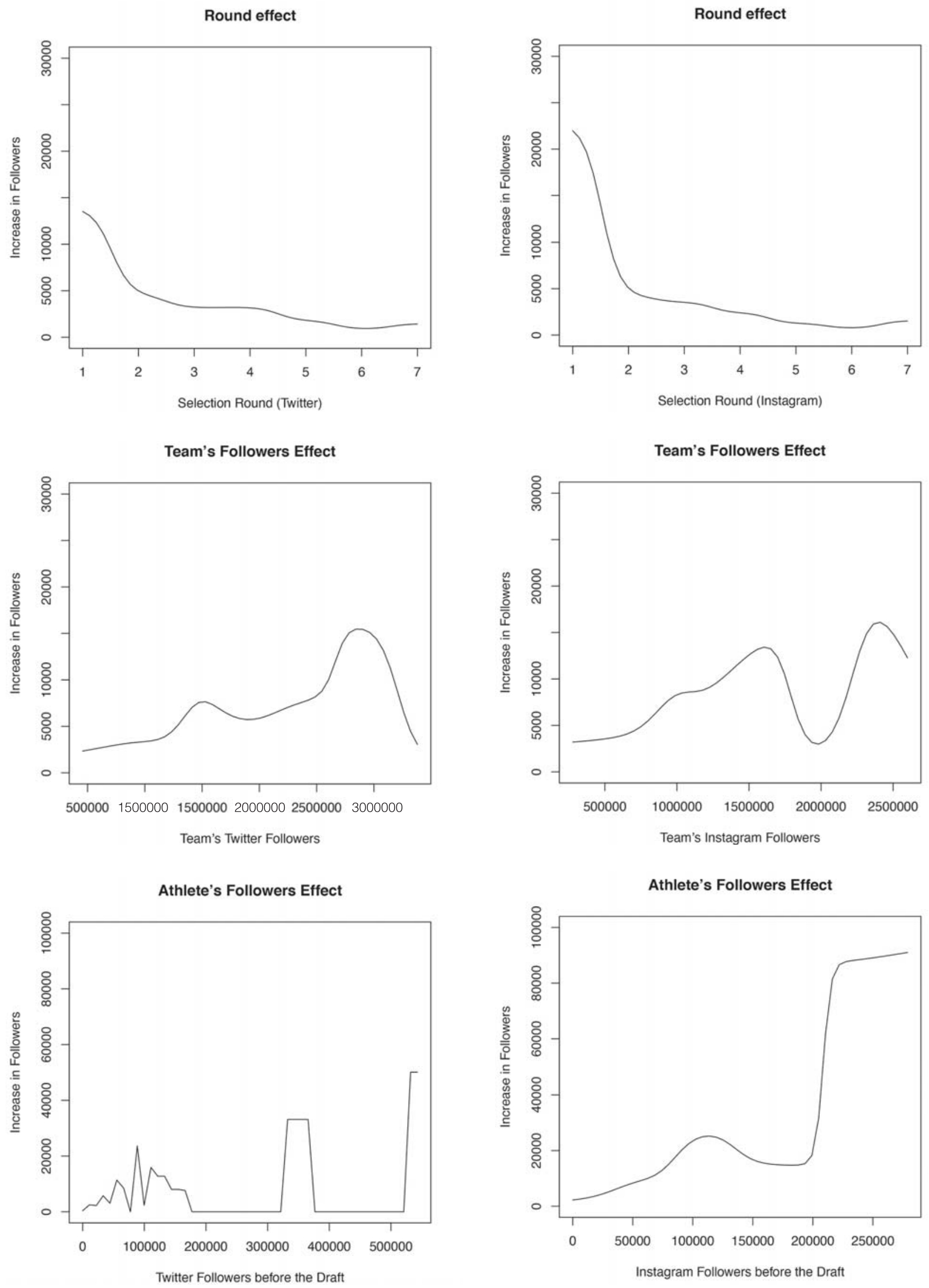

Figure 3. Results of nonparametric analysis 
athlete-, and platform-related factors on the growth of athletes' social media followers.

Results show early round selections-those that received greater media attention and a stronger quality signal-resulted in more pronounced increases in social media followers. Specific to our context, the league exerts influence on athletes through a highly publicized event and thus integrates athletes' brands into its brand architecture (Kunkel et al., 2017). From the team perspective, we found that the strength of the team's social media following influenced the subsequent effects that athletes experienced. Teams with larger social media followings have more individuals who may identify with these organizations and, thus, immediately consider athletes who join the team to be fellow in-group members (Doyle et al., 2017; Lock \& Funk, 2016). An athlete's pre-event metrics were also found to positively impact follower growth after the event, evidencing the increased benefits strong brands may reap in comparison to lesser-known brands (e.g., Baker et al., 2016; Doyle et al., 2013; Fujak et al., 2018). Taken together, the team-level and athlete-level relationships observed here evidence network effects and broaden brand architecture knowledge to include athlete brands (Kunkel et al., 2013; 2014; 2017).

Additionally, our results show that verified status significantly impacted followers on Instagram but not on Twitter. While verified Twitter users averaged 1326 more users than those who were not verified, the difference was not significant. The reason may be that the microblogging nature of Twitter (Fischer \& Reuber, 2011), which allows for more team-athlete interactions such as tagging and retweeting, gives consumers alternative options to verify the authenticity of the athlete. As a result, the effect of verified status on Twitter was less salient than that on Instagram, which constrains teams to directly reposting pictures from athletes' accounts.

Next, we used nonparametric analyses to reveal contextualized understanding to our hypotheses. These results empirically confirm the interaction between the impacts of multi-level brands within the brand architecture (Yang et al., 2009) as the athlete enters the ingroup (Lock \& Funk, 2016). Therefore, managing their social media presence strategically before the draft was beneficial for athletes in generating a strong fan base during this critical career transition. In terms of the effect of a league-related event, the visually-depicted results show a stark drop after the first round, and the differences between the first two rounds and the subsequent rounds indicate a nonlinear relationship. That is, the social media performance of top-tier players, who were selected in the first round, was amplified by intensive media exposure of the first round due to its managerial importance to the team. In line with the
Matthew effect, top players gain cumulative advantages over lesser-known players because of the special attention and the subsequent media exposure induced by the league, team, and fans (cf. Merton, 1968).

Regarding the athletes' followers effect, we found when a player with a strong network before the event was selected by a team that also had a strong follower base, the network effect was enhanced, supported by the sharp increase at the end of the figure indicating the impact of their existing followers. This finding supports double jeopardy research, showing that larger market share sport brands elicit greater brand awareness, engagement, and team-supportive behavior than smaller market share sport brands (Baker et al., 2016; Doyle et al., 2013; Fujak et al., 2018). Through this research, we provide preliminary validation that the double jeopardy effect also governs consumer responses to brands at the individual athlete level.

In aggregate, the nonparametric analyses facilitated the comparison of the impact of the variables from multiple levels and provided informative illustrations that supplement the linear regression model. The results of the nonparametric analysis visually suggest an apparent interaction between league-, team-, and athlete-level factors, allowing us to detect the joint impact of multiple brands within the brand portfolio to which an athlete is aligned. Specifically, the results highlight the importance of the athlete's effort in building a strong fan base prior to the career transition, as the impact of a team's network size is not necessarily linear. Therefore, joining a team with strong social media performance does not alone warrant the rise of an athlete's social brand. Results show an athlete's small social media fanbase moderates the positive spillover effect from the team following to the growth of the athlete's social media following. The results enrich sport branding literature by demonstrating the complex effects of related brands on the rise of an athlete brand online.

\section{Theoretical Contribution}

This research contributes to sport branding knowledge in two main aspects: brand architecture and social media. Regarding brand architecture, we extend the extant research, which has thus far been focused on the relationships between leagues and teams (Kunkel et al., 2013; Kunkel et al., 2014; Kunkel et al., 2017), by including athlete brands within this portfolio. We empirically validate the assertions of Hasaan et al. (2018) by demonstrating the NFL Draft is a league-level event that provides athletes with a platform to gain brand awareness and establish relationships with new consumers through media coverage associated with the event (e.g., Kunkel et al., 2013). 
Additionally, our findings provide evidence that consumer behavior toward athlete brands is influenced by the master brands (e.g., league and team) in the athlete's branding portfolio (Kunkel et al., 2013; Kunkel et al., 2017; Williams et al., 2013). The athlete being selected by a team within the league is a signal indicative of the quality of the athlete (e.g., Kunkel et al., 2017). This signal is more effective the earlier the athlete is drafted, indicating that brand associations of high quality trigger consumer behavior of following the athlete, and inferring the quality signal both master brands send-the league through its high quality image and the team through selecting the athlete rather than other viable alternatives-is effective in impacting athletes' brand development. Consequently, this research extends previous research (e.g., Daniels et al., 2019; Shapiro et al., 2017; Watanabe et al., 2015) by demonstrating spillover effects exist between leagues and athletes as well as teams and athletes through both providing a brand building platform and sending quality signals.

With respect to the role of social media in athlete branding, our results advance the understanding of the rise of an athlete brand in the digital environment, beyond teams heavily relying on athlete content on the team's social media channels (Anagnostopoulos et al., 2018; Parganas et al., 2015). While existing research has highlighted the importance of social brand development for athletes (e.g., Geurin-Eagleman \& Burch, 2016; Geurin, 2017; Kunkel et al., 2016), the current research shows a stronger brand (i.e., more existing followers) leads to a starker increase in followers when athletes are provided with a platform to showcase their brand. Social network effects (Katona et al., 2011) help athletes gain increased brand awareness, and the ripple effect of popularity (Dennett et al., 2016) shows those athletes with a strong brand attract more new followers than those with a weaker brand, supporting double jeopardy effects found for other high market share sport brands (e.g., Baker et al., 2016; Doyle et al., 2013; Fujak et al., 2018). In this instance, we provide evidence of networking effects within the social media behavior of sport fans by showing the effect of strong athlete brands on their increase in followers when provided with a platform to gain brand awareness. These findings extend previous literature by showcasing how off-line factors (i.e., the selection round) and online factors (i.e., the network size of the team and player before the draft and verified status) jointly impact new athlete brand on social media (Watanabe et al., 2015).

\section{Managerial Implications}

Although we focused on changes in athlete brands around the NFL Draft, implications of our findings extend well beyond this specific context to encompass athletes and other practitioners across the sport landscape. Based on our results, we discuss a number of actionable managerial implications for athletes, teams, leagues, sponsors, and collegiate programs where athletes compete as amateurs before launching their professional careers. Athletes seeking to extend their brands can capitalize on many events as catalysts for brand building, as greater media exposure leads to quicker fame building (Chang, 2018). Athletes joining a new team, especially a high-profile team, can benefit from changing their affiliation within a network of connected brands, gaining exposure and connections to new consumers. Similarly, a breakout performance during a major tournament may yield a temporary boost in media and consumer attention; athletes who are well-positioned in advance of such an event can benefit from their planning.

Overall, we advocate that athletes should place importance on the strength of the brands to which they link themselves (e.g., event, league, team), as they may place on salary and the strength of the playing roster (e.g., likelihood to win trophies or championships) in their decision making. For collegiate athletes, this long-term approach is arguably even more important as a way to set up prosperous professional careers. For example, in May 2019, Manchester United had 28.4 million Instagram followers, while their competitors Chelsea and Manchester City had 18.3 million and 12.3 million, respectively. Similarly, Ole Miss (University of Mississippi) Rebels Football had 82,000 followers on Instagram, whereas their rivals for recruiting high-quality athletes LSU (Louisiana State University) Tiger Football had 408,000 followers. Athletes should take these metrics into consideration and be cognizant of the potential long-term benefits that may emerge from partnering with team and league brands with a strong social media following. For example, if an athlete has an offer from both Manchester United and Chelsea where the Chelsea salary is higher, whilst the athlete may benefit from accepting this deal in the short-term, there are potentially greater financial benefits from the Manchester United deal in the long term. Such benefits may relate to the athlete gaining greater exposure and social media followers, attracting higher transfer fees and salaries in the future, and being able to negotiate larger endorsement deals with sponsors.

At the individual level, establishing and maintaining a strong brand requires planning, commitment, and consistent execution (Aaker, 2009). Professional 
athletes typically have a limited window of opportunity to capitalize on their personal brand, and brand-building expertise is relatively uncommon among athletes (Hodge \& Walker, 2015). Based on our findings, having a greater number of social media followers before joining a new team or starting to play professionally was associated with greater growth in followers, compounding an early advantage earned while still an amateur. Therefore, athletes should strategically manage their social media presence starting as early as possible and not defer branding activities until they begin their professional careers to build a foundation for continued success in the future. Additionally, verified account status was associated with greater increase in Instagram followers, yet not all athletes had verified accounts. Athletes should appropriately position their social media accounts, including privacy and verification settings, to take advantage of event, media, and team exposure opportunity for brand growth.

Our results further demonstrated the importance of institutional support and training on how athletes can better engage in appropriate brand-building activities (Gorbatov, Khapova, \& Lysova, 2018). Collegiate athletics departments, which frequently act as a feeder system for professional sport leagues in the United States (Pollard \& Gómez, 2015), can advise their student-athletes and help prepare them for professional careers. While National Collegiate Athletic Association (NCAA) regulations prevent collegiate student-athletes from endorsing products or monetizing their brands (NCAA, 2018), university athletics departments have begun providing athletes with tailored media content that can be used to build their online following and enhance their personal brands without violating NCAA restrictions (Novy-Williams, 2019). University athletics departments may be able to leverage brand-building support as a recruiting tool, especially for high-profile athletes who expect to go on to professional careers in major revenue sport (i.e., football and basketball). Similarly, leagues and players' unions should identify and work with potential new players to ensure they have a strong social media presence prior to league entry. This benefits not only athletes but also the teams and the league as a whole. Equally to our suggestions for athletes entering the professional arena, athletes transitioning from high school to college can be guided by this research in the sense that they should not only consider accepting scholarship or entry offers from institutions with strong teams but also those that provide their own brands with a high degree of exposure.

Sponsor brands that are considering endorsement deals with athletes should also be guided by the present findings. Sponsors should partner with athletes that not only have strong commercial appeal in their own right but also those who are likely to be drafted by high market-share teams (Biscaia, Correia, Rosado, Ross, \& Maroco, 2013). This strategy is likely to yield greater ROI for sponsors as these athletes are expected to see the greatest immediate boost. Based on the positive relationship we observed between the social media following of the drafting team and the increase in followers for the athlete, athletes who join high market-share teams are likely to see greater market penetration for their personal brands as well, with simultaneous beneficial effects on their personal favorability evaluation among sport fans and subsequent benefits to sponsors (Biscaia, Correia, Ross, \& Rosado, 2014).

\section{Limitations \& Future Research}

The current study possessed three main limitations that provide direction for researchers extending this work. First, our sampling frame for data collection required that the athletes own accounts that were publicly viewable for data to be collected. Some drafted athletes did not possess Twitter or Instagram accounts, and others had accounts that were set to private. Thus, future efforts should ascertain ways to increase the sampling frame, perhaps by drawing upon a more comprehensive initial list of athletes and by obtaining access to accounts with restrictive privacy settings (e.g., by requesting to follow the account in advance of critical trade junctures like drafts or transfer windows). In addition, replication across other countries and or contexts in which athletes are drafted (e.g., Australian Football League) would also assist in testing generalizability. Research focused on women's sport is particularly encouraged given scholars argue female athletes face additional branding challenges (Geurin, 2017; Lobpries, Bennett, \& Brison, 2018).

Second, the present research was exploratory in nature and did not consider all of the possible variables that may have explained our findings. While we accounted for variables such as athletes' pre-draft follower numbers and explain the majority of the variance of follower growth, the selection round, and the drafting team's follower numbers, there are other considerations that may contribute to explaining why people follow athletes on social media. For example, the attention directed toward athletes and the associations linked to their brands are shaped by both on-field and offfield characteristics (Arai et al., 2014). In the future, researchers should include a broader range of variables assessing the influence of aspects like the athlete's playing position, sponsorship portfolio, and other relevant group affiliations. Athletes who play in key positions (e.g., quarterback) typically attract the most media at- 
tention and possess the greatest marketing value (Garcia-del-Barrio \& Pujol, 2007; Keller, 2012) and thus may reap more benefits than others. Similarly, we did not account for the university or hometown affiliation of the athlete or the new followers. Research has shown that these affiliations provide a point of attachment and identification for fans (Heere \& James, 2007) and specifically that social media is a conduit for displaced fans to remain consumers of their hometown teams (Collins, Heere, Shapiro, Ridinger, \& Wear, 2016).

Third, our findings are reflective of a period representing growth from two days prior to and two days after the NFL Draft only. We limited this exploratory research to this point to better account for change immediately following the draft. However, athlete branding should be pursued strategically and is usually built over time (Arai et al., 2013; Geurin, 2017). In the future, researchers should investigate how athletes build their brands over longer time periods and how the actions taken by athletes, teams, and leagues may impact this process. Researchers should engage in longitudinal research and investigate the impact of athletes posting about their new team, teams making social media announcements welcoming their new members, and leagues publicizing newly joined athletes. Interactions between these, including tagging of associated accounts, the content of social media announcements, and the frequency of social media mentions, represent potential sources for valuable insight into how personal branding on social media operates in the sport environment. Longitudinal research would also assist in ascertaining how quickly fans begin to follow athletes' social media accounts after critical junctures, such as when an athlete is drafted, moves teams (e.g., Cristiano Ronaldo's transfer from Real Madrid to Juventus), or gains promotion to a higher division or relegation, to reveal branding implication in situations where the athlete's brand portfolio weakens. Better understanding of the athlete brand trajectory-whether athlete brands continue to grow or experience a hangover or drop-off effect following an immediate surge-is also a potentially fruitful area for future research.

\section{Conclusion}

This study has added to knowledge surrounding the factors determining consumers' initial engagement with athlete brands who have just experienced a change in their brand architecture. We enhance understanding related to brand architecture by demonstrating that league- and team-level factors impact the construction of athlete brands and that such influences were facilitated by social media network effects. As such, we contribute theoretically to understanding the spillover effect on fans' social media behavior within a sport brand portfolio. From this perspective, we also provide practical insights into how athletes should use social media strategically and in a manner that leverages related brands and the timing of events to positive effect. Consequently, through this research, we identify a number of opportunities for researchers to further examine and contribute to the emerging literature surrounding strategic athlete branding and athletes' social media use.

\section{References}

Aaker, D. A. (2009). Managing brand equity. New York, NY: Simon and Schuster.

Anagnostopoulos, C., Parganas, P., Chadwick, S., \& Fenton, A. (2018). Branding in pictures: Using Instagram as a brand management tool in professional team sport organisations. European Sport Management Quarterly, 18(4), 1-26.

Arai, A., Ko, Y. J., \& Kaplanidou, K. (2013). Athlete brand image: Scale development and model test. European Sport Management Quarterly, 13(4), 383-403.

Arai, A., Ko, Y. J., \& Ross, S. (2014). Branding athletes: Exploration and conceptualization of athlete brand image. Sport Management Review, 17(2), 97-106.

Baker, B. J., McDonald, H., \& Funk, D. C. (2016). The uniqueness of sport: Testing against marketing's empirical laws. Sport Management Review, 19(4), 378-390.

Biscaia, R., Correia, A., Rosado, A. F., Ross, S. D., \& Maroco, J (2013). Sport sponsorship: The relationship between team loyalty, sponsorship awareness, attitude toward the sponsor, and purchase intentions. Journal of Sport Management, 27(4), 288-302.

Biscaia, R., Correia, A., Ross, S., \& Rosado, A. (2014). Sponsorship effectiveness in professional sport: An examination of recall and recognition among football fans. International Journal of Sports Marketing and Sponsorship, 16(1), 2-18.

Cappelletti, R., \& Sastry, N. (2012). IARank: Ranking users on Twitter in near real-time, based on their information amplification potential. In 2012 International Conference on Social Informatics (pp. 70-77).

Constine, J. (2018). How Instagram's algorithm works. Tech Crunch. Retrieved from https://techcrunch.com/2018/06/01/ how-instagram-feed-works/

Daniels, J., Kunkel, T., \& Karg, A. (2019). New brands: Contextual differences and development of brand associations over time. Journal of Sport Management, 33(2), 133-147.

Dennett, A., Nepal, S., Paris, C., \& Robinson, B. (2016). TweetRipple: Understanding your Twitter audience and the impact of your tweets. In 2016 IEEE 2nd International Conference on Collaboration and Internet Computing (CIC) (pp. 256-265).

Davvetas, V., \& Diamantopoulos, A. (2016). How product category shapes preferences toward global and local brands: A Schema Theory perspective. Journal of International Marketing, 24(4), 61-81.

Doyle, J. P., Filo, K., McDonald, H., \& Funk, D. C. (2013). Exploring sport brand double jeopardy: The link between team market share and attitudinal loyalty. Sport Management Review, 16(3), 285-297.

Doyle, J. P., Lock, D., Funk, D. C., Filo, K., \& McDonald, H. (2017). 'I was there from the start:' The identity-maintenance strategies used by fans to combat the threat of losing. Sport Management Review, 20(2), 184-197. 
Eagleman, A. N. (2013). Acceptance, motivations, and usage of social media as a marketing communications tool amongst employees of sport national governing bodies. Sport Management Review, 16(4), 488-497.

FIFA. (2019a). Global transfer market report 2018: Men's football. Zurich, Switzerland: FIFA.

FIFA. (2019b). Global transfer market report 2018: Women's football. Zurich, Switzerland: FIFA.

Filo, K., Lock, D., \& Karg, A. (2015). Sport and social media research: A review. Sport Management Review, 18(2), 166-181.

Fischer, E., \& Reuber, A. R. (2011). Social interaction via new social media: (How) can interactions on Twitter affect effectual thinking and behavior? Journal of Business Venturing, 26(1), 1-18.

Fujak, H., Frawley, S., McDonald, H., \& Bush, S. (2018). Are sport consumers unique? Consumer behavior within crowded sport markets. Journal of Sport Management, 32(4), 362-375.

Geurin, A. N. (2017). Elite female athletes' perceptions of new media use relating to their careers: A qualitative analysis. Journal of Sport Management, 31(4), 345-359.

Geurin-Eagleman, A. N., \& Burch, L. M. (2016). Communicating via photographs: A gendered analysis of Olympic athletes' visual self-presentation on Instagram. Sport Management Review, 19(2), 133-145.

Gibbs, C., O’Reilly, N., \& Brunette, M. (2014). Professional team sport and Twitter: Gratifications sought and obtained by followers. International Journal of Sport Communication, 7(2), $188-213$.

Gorbatov, S., Khapova S. N., \& Lysova, E. I. (2018) Personal branding: Interdisciplinary systematic review and research agenda. Frontiers in Psychology, 9(2238), 1-17.

Grabowicz, P., Babaei, M., Kulshrestha J., \& Weber I. (2016). The road to popularity: The dilution of growing audience on twitter. Proceedings from ICWSM 2016: The Tenth International AAAI Conference on Web and Social Media. Cologne, Germany.

Hambrick, M. E., Frederick, E. L., \& Sanderson, J. (2015). From yellow to blue: Exploring Lance Armstrong's image repair strategies across traditional and social media. Communication \& Sport, 3(2), 196-218.

Hasaan, A., Kerem, K., Biscaia, R., \& Agyemang, K. (2018). A conceptual framework to understand the creation of athlete brand and its consequences. International Journal of Sports Marketing and Management, 18(3), 169-198.

Hayes, A. F., \& Cai, L. (2007). Using heteroskedasticity-consistent standard error estimators in OLS regression: An introduction and software implementation. Behavior Research Methods, 39(4), 709-722.

Hill, R. C., Griffiths, W. E., \& Lim, G. C. (2011). Principles of econometrics. Hoboken, NJ: Wiley.

Hodge, C., \& Walker, M. (2015). Personal branding: A perspective from the professional athlete-level-of-analysis. International Journal of Sport Management and Marketing, 16(1-2), 112-131.

Katona, Z., Zubcsek, P. P., \& Sarvary, M. (2011). Network effects and personal influences: The diffusion of an online social network. Journal of Marketing Research, 48(3), 425-443.

Koumchatzky, N., \& Andryeyev, A. (2017). Using deep learning at scale in Twitter's timelines. Twitter. Retrieved from https:// blog.twitter.com/engineering/en_us/topics/insights/2017/ using-deep-learning-at-scale-in-twitters-timelines.html

Kunkel, T., Scott, O., \& Beaton, A. (2016). Interview with Michael Lahoud, professional soccer player: Lessons of personal athlete branding via social media. International Journal of Sport Communication, 9(4), 415-423.

Kunkel, T., Funk, D., \& Hill, B. (2013). Brand architecture, drivers of consumer involvement, and brand loyalty with professional sport leagues and teams. Journal of Sport Management, 27(3), 177-192.
Kunkel, T., Funk, D. C., \& King, C. (2014). Developing a conceptual understanding of consumer-based league brand associations. Journal of Sport Management, 28, 49-67.

Kunkel, T., Funk, D. C., \& Lock, D. (2017). The effect of the league brand on the relationship between the team brand and behavioral intentions: A formative approach examining brand associations and brand relationships. Journal of Sport Management, 31(4), 1-43.

Lee, M. J. (1996). Methods of moments and semiparametric econometrics for limited dependent variable models. New York, NY: Springer-Verlag.

Lobpries, J., Bennett, G., \& Brison, N. (2018). How I perform is not enough: Exploring branding barriers faced by elite female athletes. Sport Marketing Quarterly, 27(1), 5-17.

Lock, D. J., \& Funk, D. C. (2016). The multiple in-group identity framework. Sport Management Review, 19(2), 85-96.

Lock, D., \& Heere, B. (2017). Identity crisis: A theoretical analysis of 'team identification' research. European Sport Management Quarterly, 17(4), 413-435.

Lynch, J., \& Schuler, D. (1994). The matchup effect of spokesperson and product congruency: A schema theory interpretation. Psychology and Marketing, 11(5), 417-445.

Marwick, A. E. (2015). You may know me from YouTube: (Micro-) celebrity in social media. In P. D. Marshall \& S. Redmond (Eds.), A companion to celebrity (pp. 333-350). Chichester, UK: John Wiley \& Sons.

McCall, G. S. (2018). Strategies for quantitative research: Archaeology by numbers. London, UK: Routledge.

Merton, R. K. (1968). The Matthew effect in science: The reward and communication systems of science are considered. Science, 159(3810), 56-63.

National Collegiate Athletic Association [NCAA]. (2018). 2018-2019 NCAA Division I manual. Indianapolis, IN: National Collegiate Athletic Association.

Nejad, M. G., Sherrell, D. L., \& Babakus, E. (2014). Influentials and influence mechanisms in new product diffusion: An integrative review. Journal of Marketing Theory and Practice, 22(2), 185-208.

Novy-Williams, E. (2019). NFL prospects become social-media stars long before draft. Bloomberg. Retrieved from https://www.bloomberg.com/news/articles/2019-04-25/ who-s-in-the-nfl-draft-social-media-stars

Ottovordemgentschenfelde, S. (2017). 'Organizational, professional, personal:' An exploratory study of political journalists and their hybrid brand on Twitter. Journalism, 18(1), 64-80.

Parganas, P., Anagnostopoulos, C., \& Chadwick, S. (2015). 'You'll never tweet alone:' Managing sports brands through social media. Journal of Brand Management, 22(7), 551-568.

Parmentier, M. A., \& Fischer, E. (2012). How athletes build their brands. International Journal of Sport Management and Marketing, 11(1-2), 106-124.

Pegoraro, A. (2010). Look who's talking: Athletes on Twitter: A case study. International Journal of Sport Communication, 3(4), 501-514.

Pegoraro, A., \& Jinnah, N. (2012). Tweet'em and reap'em: The impact of professional athletes' use of Twitter on current and potential sponsorship opportunities. Journal of Brand Strategy, 1(1), 85-97.

Pollard, R., \& Gómez, M. Á. (2015). Comparison of home advantage in college and professional team sports in the United States. Collegium Antropologicum, 39(3), 583-589.

Pucci, D. (2017, May 5). ESPN ratings: Growth for NFL Draft first round, slight declines for subsequent rounds. Awful Announcing. Retrieved from http://awfulannouncing.com/ratings/ espn-ratings-growth-nfl-draft-first-round-slight-declines-subsequent-rounds.html 
Rubin, P. H. (1978). The theory of the firm and the structure of the franchise contract. Journal of Law and Economics, 21, 223-233.

Rust, R. (1988). Flexible regression. Journal of Marketing Research, 25(1), 10-24.

Shapiro, S. L., DeShriver, T. D., \& Rasher, D. A. (2017). The Beckham effect: Examining the longitudinal impact of a star performer on league marketing, novelty, and scarcity. European Sport Management Quarterly, 17(5), 610-634.

Sundar, S. S. (2007). The MAIN model: A heuristic approach to understanding technology effects on credibility. In M. J. Metzger \& A. J. Flanagin (Eds.), Digital media, youth, and credibility (pp. 73-100). Cambridge, MA: MIT Press.

Steiner, W. J., Brezger, A., \& Belitz, C. (2007). Flexible estimation of price response functions using retail scanner data. Journal of Retailing and Consumer Services, 14(6), 383-393.

Van Heerde, H. J. (2017). Non-and semiparametric regression models. In P. S. Leeflang, J. E. Wieringa, T. H. Bijmolt, \& K. H. Pauwels (Eds.), Advanced methods for modeling markets (pp. 555-579). Cham, Switzerland: Springer.

Vallaster, C., \& De Chernatony, L. (2005). Internationalization of services brands: The role of leadership during the internal brand building process. Journal of Marketing Management, 21(1-2), 181-203.
Watanabe, N., Yan, G., \& Soebbing, B. P. (2015). Major League Baseball and Twitter usage: The economics of social media use. Journal of Sport Management, 29(6), 619-632.

Watanabe, N. M., Yan, G., \& Soebbing, B. P. (2016). Consumer interest in Major League Baseball: An analytical modeling of Twitter. Journal of Sport Management, 30(2), 207-220.

Williams, A., Kim, D. Y., Agyemang, K., \& Martin, T. G. (2015). All brands are not created equal: Understanding the role of athletes in sport-brand architecture. Journal of Multidisciplinary Research, 7(3), 75-86.

Yang, Y., Shi, M., \& Goldfarb, A. (2009). Estimating the value of brand alliances in professional team sports. Marketing Science, 28(6), 1095-1111.

Zhang, L., Peng, T. Q., Zhang, Y. P., Wang, X. H., \& Zhu, J. J. (2014). Content or context: Which matters more in information processing on microblogging sites. Computers in Human Behavior, 31, 242-249.

\section{Acknowledgment}

This research was supported by the Sport Industry Research Center at Temple University. 
Copyright of Sport Marketing Quarterly is the property of Fitness Information Technology, Inc. and its content may not be copied or emailed to multiple sites or posted to a listserv without the copyright holder's express written permission. However, users may print, download, or email articles for individual use. 